\title{
Revisão Sistemática da Literatura sobre o uso de Aplicativos Móveis sem fins Educacionais em Smartphones Aplicados aos Processos de Ensino-Aprendizagem
}

\section{Systematic review of the literature on the use of mobile applications without educational purposes on Smartphones applied to teaching-learning processes}

Virginia de Sousa Venega ${ }^{1}$, Denis da Silva Passos², Walisson Pereira de Sousa ${ }^{3}$

\section{RESUMO}

Este artigo apresenta uma Revisão Sistemática da Literatura cujo objetivo foi identificar e analisar contextos que apresentem a utilização de aplicativos móveis sem fins educacionais em smartphones aplicados aos processos de ensino e aprendizagem. A fim de conhecer o panorama das publicações científicas nacionais sobre esta prática, este estudo buscou conhecer quais os softwares que têm sido utilizados e as abordagens pedagógicas adotadas nestes contextos. Foram analisados artigos submetidos a revistas e anais de conferências nacionais voltados ao tema de Informática na Educação e as primeiras impressões dos dados extraídos é que tem havido um aumento de publicações apresentando experimentações de aprendizagem móvel. Contudo, apesar do aumento de publicações sobre a temática, especialmente no ano de 2016, consideramos que ainda existe um longo caminho a ser percorrido para garantir que estes casos se estendam a um número maior de escolas. Por vivenciarmos um período em que o crescimento do uso de celulares tem se mostrado uma tendência, os dados aqui levantados apontam que o cenário da educação atual se mostra cada vez mais propício a utilizações de aplicações móveis em sala de aula.

Palavras-Chave: Aprendizagem Móvel, Smartphones, Educação.

\section{ABSTRACT}

This article presents a Systematic Review of Literature aiming to identify and analyze contexts that present non-educational applications in smartphones applied to teaching and learning processes. In order to know the panorama of the scientific publications about this practice, this study sought to know which softwares were used and whitch pedagogical approaches adopted in these contexts. Articles submitted to journals and conference proceedings focused on the subject of Informatics in Education were analyzed and as first impressions of the extracted data, have been an increase of publications presenting mobile learning experiments. However, despite the increase in publications on a subject, especially in the year 2016, we believe that there is still a long way to go to ensure that these cases extend to a larger number of schools. By living a period in which the growth of the use of mobile phones is a tendency, the data here raised indicate that the current educational scenario is increasingly conducive to use of mobile applications in the classroom.

Keywords: Mobile Learning, Smartphones, Education.
Especialista em Desenvolvimento de Aplicações Web (UNOPAR). Professora do Ensino Básico, Técnico Tecnológico do Instituto Federal do Tocantins - Campus Avançado de Formoso do Araguaia (IFTO).

E-mail: virginia.venega@ifto.edu.br

Mestrando em Modelagem Computacional (UFT).

Mestrando em Ciência da Computação (UFG). Professor do Ensino Básico, Técnico e Tecnológico do Instituto Federal do Tocantins - Campus Araguaína (IFTO). 


\section{INTRODUÇÃO}

"A história da vida [...], é uma série de situações estáveis, pontuadas em intervalos raros por eventos importantes que ocorrem com grande rapidez e ajudam a estabelecer a próxima era estável"'. É apoiado nesta conjetura, que Castells (2016) afirma - a respeito da Revolução da Tecnologia da Informação -, que a Revolução Digital da Tecnologia é um evento histórico de magnitude semelhante à Revolução Industrial do século XVIII e acontecimentos como este ocasionam impactos significativos de ordem econômica, social e cultural.

Este "alvorecer da era digital" trouxe consigo a revolução das telecomunicações, a cibercultura e as comunidades virtuais (SANTAELLA, 2003, p.173). Nesse sentido há uma convergência para a constituição de novos meios de comunicação, pensamento e trabalho. Estas mudanças de alcance global vieram para alterar a nossa cultura de forma permanente (LÉVY, 1999).

Segundo Lévy (1999, p.29), as questões antropológicas e sociológicas consequentes da rápida evolução tecnológica vêm sendo sentidas há pelo menos quatro décadas. Segundo o autor, o não acompanhamento do desenvolvimento tecno-social tende a excluir de maneira radical os indivíduos que encontram dificuldades na compreensão e apropriação destes novos conhecimentos. Para ele, a "aceleração é tão forte e tão generalizada que até mesmo os mais 'ligados' encontram-se, em graus diversos, ultrapassados pela mudança" uma vez que ninguém pode participar ativamente de todas as transformações de perto.

Para Castells (2016), tanto o espaço quanto o tempo estão sendo alterados graças aos efeitos do paradigma da tecnologia da informação. $O$ tradicional espaço de lugares tende a dar lugar ao espaço de fluxos. Segundo o autor, a sociedade passou a se construir em torno de fluxos - de capital, de informação, de tecnologia.... -, e tais fluxos tem como suporte material as telecomunicações, sistemas de transmissão, transporte em alta velocidade, entre outros. Nesse sentido a sociedade caminha para um 'desmembramento' entre espaços de fluxos e espaços de lugares, cuja tendência é a constituição de lugares conectados e lugares desconectados.

Os reflexos desta sociedade em rede têm sido observados nas últimas décadas através do avanço considerável no campo de conhecimento das Tecnologias Digitais de

\footnotetext{
${ }^{1}$ Frase de Stephen J. Gould, paleontólogo, citado por Manuel Castells no livro "A sociedade em rede". (CASTELLS, 2016, p.87).
} 
Informação e Comunicação (TDICs). No entanto, apesar de ser evidente que as TDIC têm causado grande impacto em todos os segmentos da sociedade, Almeida e Valente (2012) afirmam que:

na Educação, a presença destas tecnologias é muito pouco significativa e seu potencial é pouco explorado. Ainda não observamos nos processos de ensino e de aprendizagem, em distintos níveis, do Básico ao Superior, os mesmos impactos e transformações visivelmente identificados em outros segmentos, tais como no sistema bancário, nos processos administrativos, nos serviços e nas empresas em geral. (ALMEIDA; VALENTE, 2012, p.58)

Nesse sentido, cumpre informar que foi na década de 1980 que surgiram as primeiras políticas públicas voltadas à inserção das tecnologias de informação e comunicação nas escolas. Desde este período, " a educação é considerada um dos pilares das políticas de inclusão digital da população" (ALMEIDA, 2015, p. 720) através da disponibilização de aparatos tecnológicos, infraestrutura, conexão à internet e formação de professores.

No entanto, embora existam esforços em promover a utilização de recursos tecnológicos no âmbito educacional e cotidiano, fatores diversos impedem que uma maturidade da inclusão digital de forma sólida e efetiva aconteça. Segundo Almeida (2015),

devido à extensão territorial do Brasil e ao quantitativo de escolas urbanas e rurais de distintas realidades e regiões sócio geográficas, ligadas a redes de ensino com diretrizes educacionais específicas, até o presente os objetivos dos programas e projetos realizados não atingiram a universalização. A par disso, as constantes mudanças na gestão pública dificultam a continuidade das ações e impedem sua capilaridade e sustentabilidade. Apesar do crescimento considerável na quantidade de laboratórios de informática implantados nas escolas e dos projetos e programas de inserção de tecnologias móveis nas escolas, ainda há muito a ser feito para a integração entre o currículo e as TIC. (ALMEIDA, 2015, p. 722).

Um dos problemas frequentemente elencados é a formação do professor. De acordo com o Projeto Padrões de Competências em TIC para Professores - (ICT-CST) da Organização das Nações Unidas para a Educação, a Ciência e Cultura - UNESCO, os professores

[...] precisam estar preparados para ofertar autonomia a seus alunos com as vantagens que a tecnologia pode trazer. As escolas e salas de aula, [...], devem ter professores equipados com recursos e habilidades em tecnologia que permitam realmente transmitir o conhecimento ao mesmo tempo que se incorporam conceitos e competências em TIC. (UNESCO, 2009, p.3)

Nesse sentido, Almeida (2016, p.526) questiona a integração entre os espaços de aprendizagem (formais, não formais e informais) na "complementaridade e integração entre contextos com o uso das Tecnologias Móveis com Conexão Sem Fio à internet (TMSF) " associados à computação ubíqua.

A ubiquidade reconfigura os espaços de lugar e de fluxos de informações midiáticas pela presença transparente (onipresença) de dispositivos e mídias digitais no cotidiano (LEMOS, 2004), cuja convergência potencializa a representação do 
pensamento humano e as interações sociais. O que antes era considerado ciberespaço digital se entrelaça com o espaço físico, convergindo com o movimento da vida no cotidiano (JENKINS, 2008) e criando um espaço híbrido intersticial de hipermobilidade (SANTAELLA, 2007) e multimodalidade pela combinação de palavras, sons, imagens, animações e vídeos, que influi nas concepções de conhecimento e nos processos de aprender, fazendo surgir o que Santaella (2013) denomina aprendizagem ubíqua. (ALMEIDA, 2016, p. 528)

Este artigo apresenta, no cenário das TMSF e aprendizagem móvel e ubíqua, uma revisão sistemática da literatura sobre o uso de aplicativos móveis sem fins educacionais aplicados aos processos de ensino e aprendizagem. Com a popularização do uso dos aparelhos celulares denominados smartphones ${ }^{2}$ e considerando a crescente lista de aplicativos disponíveis nas lojas virtuais (App Stores) que de tempos em tempos têm conquistado a população (seja pelos serviços inovadores oferecidos, modismos ou usabilidade), este estudo investigou a utilização dessas aplicações para fins educacionais, mesmo que não tenham sido concebidas com essa intencionalidade.

\subsection{Fundamentação}

Segundo dados de pesquisa realizada em 2013 pela Secretaria Nacional de Juventude sobre o perfil de jovens brasileiros, observou-se que $89 \%$ do público entrevistado possuía telefone celular contra apenas $11 \%$ que não possuíam ou não responderam. Quanto ao uso destes aparelhos, verificou-se que depois de "fazer e/ou receber ligações", a segunda maior utilidade atribuída ao aparelho era a de "comunicar-se via mensagens de texto". (BRASIL, SNJ, 2013, p.37)

Em 2014, de acordo com pesquisa realizada pelo IBGE, pela primeira vez no Brasil, o uso do telefone celular para acesso à Internet superou o uso dos computadores (Erro! Fonte de referência não encontrada.). No ano seguinte este cenário apresentou alta chegando a 92,1\% (IBGE, 2016, p. 43). Esses dados evidenciam que a sociedade tem aprendido rapidamente a conviver com a acelerada evolução dos aparatos tecnológicos (KENSKI, 2004).

\footnotetext{
${ }^{2}$ Smartphones, em tradução literal significa "telefone inteligente". Refere-se a aparelhos híbridos entre celulares e computadores. Não tem o hardware potente de um computador pessoal, mas também não são tão simples quanto um telefone. (Thiago Barros, 2012, http://www.techtudo.com.br/artigos/ noticia/2011/12/o-que-e-smartphone-e-para-queserve.html )
} 
Venega, V.S., Passos, D.S., Sousa, W.P.

Revisão Sistemática da Literatura sobre o uso de Aplicativos Móveis sem fins Educacionais em Smartphones Aplicados aos Processos de Ensino-Aprendizagem

Figura 1. Demonstrativo do uso de Internet por aparelhos

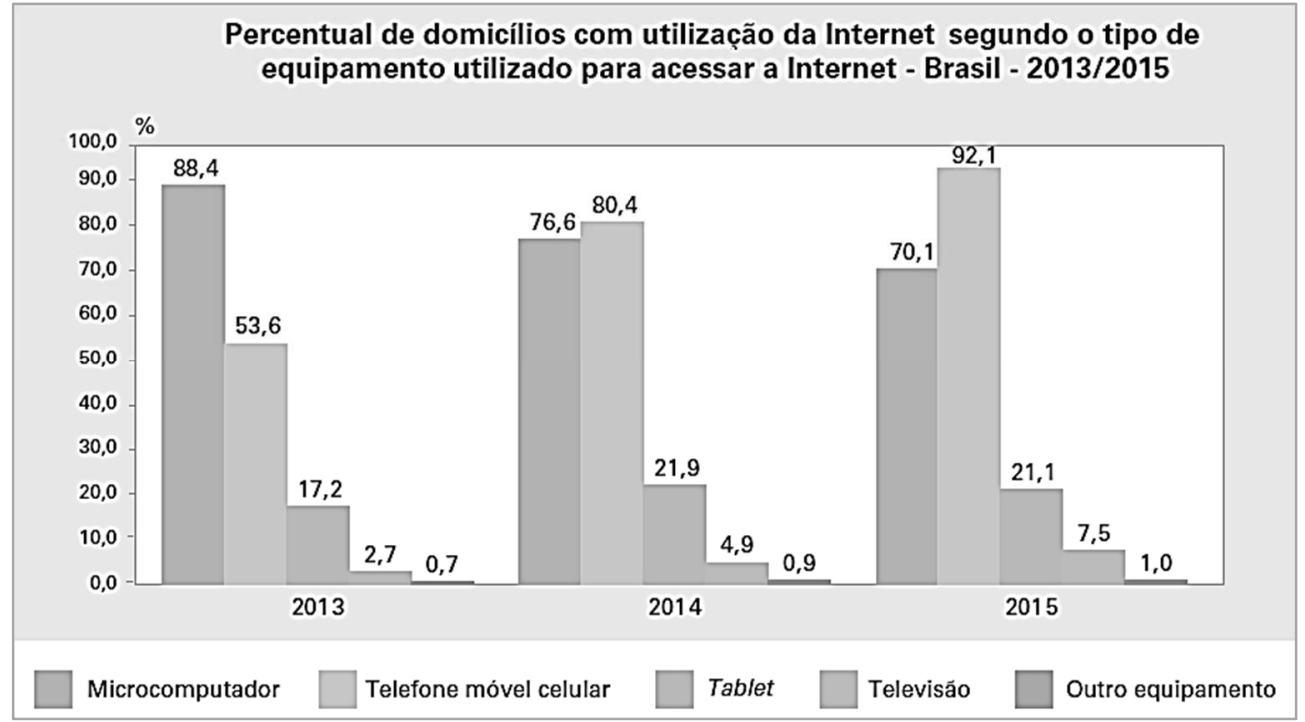

Fonte: IBGE (2016)

No entanto, embora professores e estudantes utilizem as mídias digitais socialmente, no espaço escolar, esse tipo de interação parece não acontecer de maneira fluida, uma vez que se faz necessário a construção pedagógica dessas interações considerando uma "intencionalidade educativa" (PEREIRA et al., 2016a) Segundo Almeida (2016, p.530), "neste primeiro quarto do século XXI os instrumentos culturais marcantes são as TDIC, e mais especificamente as TMSF e seus aplicativos, com [alto] potencial de ubiquidade".

Valendo-se da disseminação das TMSF e dos apps, é mister que hajam esforços para garantirmos a integração das TIC junto à educação. O uso de dispositivos móveis ilustrase como excelente alternativa na perspectiva da aprendizagem, possibilitando a ampliação dos espaços educativos e a descentralização do acesso ao saber. (MARINHO et al., 2015)

A razão pela qual este estudo se ateve a utilização de dispositivos móveis nas práticas educativas, entre outros, vai de encontro ao fato que apesar das iniciativas em dispor de ambientes com aparatos tecnológicos nas escolas, muitas instituições de ensino dispõem de ambientes carentes de infraestrutura e sem a manutenção necessária (PEREIRA et al., 2016a). Na perspectiva do uso de dispositivos móveis, o aluno pode trazer seu próprio dispositivo sem onerar a instituição por causa disso.

Este artigo se atém ao uso dos aplicativos sem fins educacionais (e não o contrário) pela percepção da notável resistência encontrada por parte de professores em incorporar as TIC na educação (LOPES et al., 2016). Isso ocorre muitas vezes em virtude da falta de contato com os aparatos tecnológicos e a sensação de descontrole do contexto de aprendizagem. Os aplicativos sem fins educacionais, por outro lado, são amplamente 
utilizados fora da escola por alunos e professores. A barreira de manipular a aplicação já foi transposta, existe uma intimidade e controle no uso do mesmo. Esse contexto permite que professores e alunos consigam então utilizar os recursos oferecidos pelo dispositivo mobile direcionando o foco apenas para as questões de aprendizagem, refutando assim, o antigo conceito de que mobile learning limitar-se-ia apenas à utilização dos dispositivos móveis. (MARINHO et al., 2015)

Portando, nesse contexto de espaços de fluxos, a aquisição de conhecimento não se encontra mais confinada para dentro dos muros da escola. Pode-se adquirir conhecimento em qualquer lugar e isso não deve ser visto como uma ameaça à figura do professor, pelo contrário (FREITAS, 2016). É necessário que os educadores desta nova era passem a tirar proveito disso como forma de melhor preparar o estudante e tornar a aprendizagem real e significativa.

\section{MATERIAIS E METODOS}

Com o objetivo conhecer o panorama de publicações nacionais sobre a utilização de aplicativos móveis não educacionais aplicados aos processos de ensino e aprendizagem, conduziu-se uma Revisão Sistemática da Literatura (RSL) sobre o tema. A RSL realizada neste trabalho adotou a metodologia proposta por Kitchenham e Charles (2007) e está dividida em três etapas: planejamento, realização e relatório.

\subsection{Planejamento da Revisão Sistemática da Literatura}

Para a realização desta RSL foram definidas cinco questões de pesquisa a fim de nortear a seleção dos estudos analisados nesta revisão. A seguir são apresentadas as questões de pesquisa:

QP1. Qual o panorama atual das publicações científicas nacionais sobre a utilização de aplicativos não educacionais em aprendizagem móvel?

QP2. Quais são as áreas de conhecimento que mais tem se beneficiado com experimentos dessa natureza?

QP3. Quais etapas do ensino (Fundamental, Médio e Superior) mais tem se beneficiado com experimentos dessa natureza?

QP4. Como os professores tem encarado o desafio de incorporar a aprendizagem móvel nas aulas?

QP5. As experimentações têm sido associadas às teorias de aprendizagem?

2.2. Fonte de Busca e Período de Publicação

Para realização desta RSL, considerou-se artigos na área de interesse dos últimos 6 
anos (2011-2016) e a busca foi feita nas seguintes bases: Simpósio Brasileiro de Informática na Educação - SBIE, Workshop de Informática na Escola - WIE, Workshops do Congresso Brasileiro de Informática na Educação - WCBIE, Jornada de Atualização de Informática na Educação - JAIE; Workshop de Desafios da Computação Aplicada à Educação - WDCAE, Revista Brasileira de Informática na Educação - RBIE, Revista Novas Tecnologias na Educação - Renote, Scientific Eletronic Library Online - SciELO e a base Scopus (Elsevier).

\subsection{Estratégia de Busca e Seleção de Trabalhos}

Para realizar a busca automática foi elaborada uma string de busca baseada em termos importantes e suas variações, fundamentados nas perguntas de pesquisa.

Desse modo a string de busca da RSL foi gerada a partir da combinação dos termos e seus sinônimos usando os operadores lógicos OR e AND. Logo, a string de busca utilizada foi: "mobile learning" OR "(aprendizagem OR aprendizado) móvel" OR ("mobile device" OR smartphone OR "dispositivos móveis" OR "dispositivo móvel" OR celular) AND (education $\mathrm{OR}$ educação $\mathrm{OR}$ educational) $\mathrm{OR}$ (ubiquidade $\mathrm{OR}$ ubiquitousness $\mathrm{OR}$ ubiquitous).

Para a seleção dos estudos da RSL, foram definidos os seguintes critérios de inclusão e exclusão:

Tabela 1 - Critérios de Inclusão e Exclusão da RSL

\begin{tabular}{ll}
\hline \multicolumn{1}{c}{ Critérios de Inclusão (CI) } & \multicolumn{1}{c}{ Critérios de Exclusão (CE) } \\
\hline Cl1 - Artigos em língua portuguesa & CE1 - Artigos em língua estrangeira \\
\hline Cl2 - Publicações entre os anos de 2011 e 2016 & $\begin{array}{l}\text { CE2 - Publicações que apresentem casos de uso } \\
\text { com aplicativos educacionais }\end{array}$ \\
\hline $\begin{array}{l}\text { Cl3 - Artigos que tratem de aplicações móveis } \\
\text { voltadas para uso em smartphones }\end{array}$ & $\begin{array}{l}\text { CE3 - Artigos que tratem de aplicações móveis } \\
\text { voltadas para dispositivos móveis que não sejam } \\
\text { do tipo smartphones }\end{array}$ \\
\hline $\begin{array}{l}\text { Cl4 - Aplicativos sem fins educacionais utilizados } \\
\text { para fins educacionais }\end{array}$ & $\begin{array}{l}\text { CE4 - Artigos que apresentem estudos não } \\
\text { realizados no território brasileiro }\end{array}$ \\
\hline $\begin{array}{l}\text { Cl5 - Artigos que apresentem estudos sobre a } \\
\text { temática pesquisada realizados no âmbito do } \\
\text { território brasileiro }\end{array}$ & $\begin{array}{l}\text { CE5 - Artigos com quantidade de páginas } \\
\text { inferiores a 4. }\end{array}$ \\
\hline
\end{tabular}

Para proceder à seleção dos estudos primários algumas etapas tiveram que ser cumpridas. A descrição das etapas de seleção pode ser vista na Tabela 2. 


\begin{tabular}{|c|c|}
\hline 1 Etapa & $\begin{array}{l}\text { Após realização de buscas nas bases de dados propostas, foram excluídos os títulos não } \\
\text { relevantes às questões investigadas. O critério de exclusão utilizado foi a leitura dos } \\
\text { títulos, resumos e palavras chaves dos estudos recuperados. Os artigos em que houve } \\
\text { dúvida quanto à inclusão ou exclusão foram mantidos e os duplicados foram excluídos. }\end{array}$ \\
\hline 2a Etapa & $\begin{array}{l}\text { Nesta etapa foi realizado a leitura dos resumos, introdução e conclusão dos artigos } \\
\text { selecionados na etapa anterior. }\end{array}$ \\
\hline 3a Etapa & $\begin{array}{l}\text { Na etapa } 3 \text { foi feita a leitura integral dos artigos selecionados na etapa anterior, sendo } \\
\text { então realizada nova filtragem definindo assim os estudos aptos a participar da RSL. }\end{array}$ \\
\hline 4ª Etapa & Extração dos dados \\
\hline
\end{tabular}

Após cumpridas as etapas relacionadas na Tabela 2, foram selecionados 13 artigos para esta revisão sistemática da literatura. $O$ detalhamento dos estudos retornados em cada uma das etapas do processo de seleção podem ser vistas em goo.gl/f3ALSU.

\section{RESULTADOS E DISCUSSAOO}

Com o objetivo de organizar e facilitar a síntese dados, foram gerados os gráficos abaixo (Figura 2 e Erro! Fonte de referência não encontrada.), onde o primeiro apresenta a relação entre a quantidade de publicações por ano e o segundo, o quantitativo de estudos retornados por fonte de busca. Ao analisar a Figura 2, é possivel observar que nos três primeiros anos alvo desta RSL apenas 2 artigos foram publicados, no entanto, a partir de 2014 ocorreu um crescimento no número de publicações (especialmente em 2016), o que se apresenta como uma tendência de pesquisa por parte da comunidade científica.

A Erro! Fonte de referência não encontrada., por sua vez, evidencia que o WIE Workshop de Informática na Escola, que tem por finalidade divulgar iniciativas nacionais de aplicação das TIC na educação, em sido escolhido como um dos principais meios de divulgação para iniciativas desta natureza.

Figura 2. Quantidade retornada de por ano de publicação

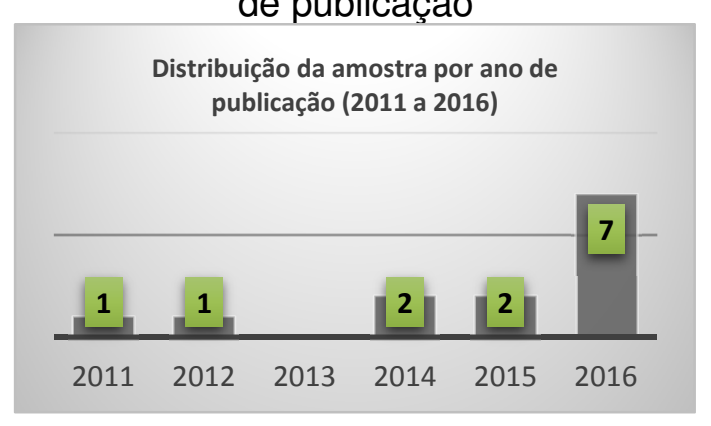

Figura 3. Quantidade retornada por fonte de busca

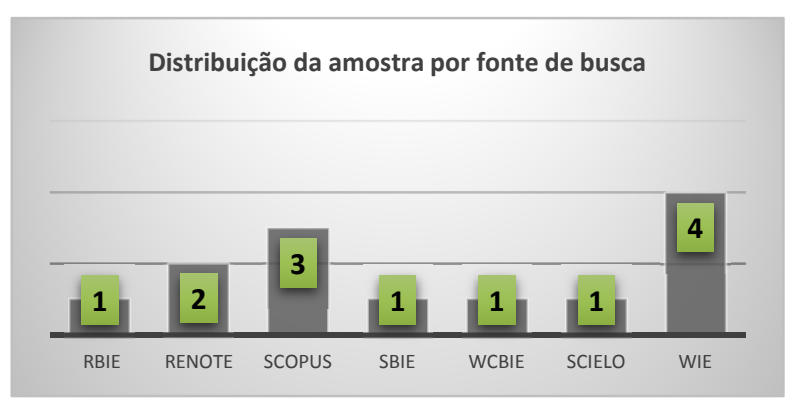


O estudo realizado buscou responder as questões levantadas nesta RSL. Desta forma, apresentamos as principais conclusões relacionadas ao panorama do uso de aplicativos móveis sem fins educacionais no processo de ensino no Brasil bem como as características dos estudos analisados.

\section{QP1. Qual o panorama atual das publicações científicas nacionais sobre a utilização} de aplicativos não educacionais em aprendizagem móvel?

Através da realização da RSL foi possível perceber que as publicações científicas sobre a utilização de aplicativos mobile sem fins educacionais no ensino e aprendizagem ainda é uma iniciativa tímida. No entanto, ao analisarmos a Figura 2 (amostra por ano de publicação), observa-se que o ano de 2016 foi aquele em que houve a maior incidência de publicações sobre o tema nas bases pesquisadas, representando 54\% das publicações. Essa informação nos leva a crer que existe uma tendência ao crescimento de publicações e práticas relacionadas a este tema para os próximos anos.

É importante salientar que a disseminação do uso de dispositivo móveis e a disponibilização de acesso à Internet tem ganhado força e espaço em nossa sociedade. Segundo pesquisa divulgada pelo Comitê Gestor da Internet no Brasil (2016), o crescimento do uso de celulares tem se mostrado uma tendência e em 2015, o celular foi citado como o equipamento mais utilizados por alunos para acesso à internet (91\%) contra 80\% no ano de 2014, e esses números tem aumentado. (TIC, 2016, p. 146).

Dessa forma, observa-se um cenário mais propício para a utilização de dispositivos móveis em sala de aula, e isso configura ambiente perfeito para a aplicação de aprendizagem móvel. Portanto, estas tecnologias podem ser ainda muito exploradas no sentido de ampliar e enriquecer as atividades educacionais uma vez que garantem a possibilidade de acesso a informação e conhecimento em qualquer horário e local, viabilizando assim, novas formas de aprendizagem.

\section{QP2. Quais são as áreas de conhecimento que mais tem se beneficiado com experimentos dessa natureza?}

Através da análise dos dados coletados, observou-se que os estudos abrangeram diversas áreas, como Artes, Matemática, Administração de Empresas e Educação Ambiental. No entanto, a área que houve maior incidência de experimentos foi a de Formação de Professores. A lista dos artigos recuperados nesta pesquisa e suas respectivas áreas podem ser vistas em goo.gl/EPyU3a. 
Em relação aos aplicativos utilizados nestas práticas ${ }^{3}$, observou-se que $26 \%$ dos estudos analisados utilizaram aplicativos de vídeos (gravadores e editores) seguido pelo aplicativo de comunicação Whatsapp (19\%) e aplicativos de fotos (15\%). Esses dados reforçam a percepção de que o uso de apps utilizados no cotidiano de professores e alunos contribuem para que o foco durante a aprendizagem permaneça nos processos de ensino e aprendizagem, e não nos aparatos tecnológicos, que neste contexto apresentam-se como novas ferramentas pedagógicas.

\section{QP3. Quais etapas do ensino (Fundamental, Médio e Superior) mais tem se beneficiado com experimentos dessa natureza?}

A revisão sistemática da literatura também buscou responder quais etapas de ensino foram contempladas nos estudos em questão. De forma próxima à QP2, a etapa com maior incidência de intervenções com o uso de aplicativos móveis sem fins educacionais foram as formações continuadas, relacionadas à formação de professores ${ }^{4}$. Esse dado se mostra muito importante por evidenciar que existe a preocupação em melhor capacitar os profissionais da educação para o uso das TDIC.

No estudo apresentado por Marçal et al. (2016), examinou-se a utilização das mensagens SMS em um curso a distância que atendeu 474 professores de escolas públicas. O estudo buscou verificar se o envio de notificações via SMS aos alunos participantes do curso (amostragem que contou com 100 alunos) melhorava a participação dos alunos no curso.

O trabalho de Hitzschky et al. (2016) relatou a experiência da utilização de dispositivos móveis em duas aulas de campo de um curso de formação que envolveu professores e alunos. Durante as aulas de campo foram utilizadas diferentes tecnologias móveis que foram desde Redes Sociais a ferramentas de gravação e edição de vídeo. Segundo os autores, após a aula de campo, observou-se uma mudança de comportamento dos alunos, que se viram como "reais protagonistas do conhecimento". (HITZSCHKY et al., 2016)

\section{QP4. Como os professores tem encarado o desafio de incorporar a aprendizagem móvel nas aulas?}

Nenhum dos estudos selecionados na RSL respondeu diretamente à QP4. No entanto, ao longo dos textos pistas foram sendo deixadas revelando apontamentos

\footnotetext{
${ }^{3}$ Gráfico com detalhamento dos aplicativos sem fins educacionais mais utilizados em contextos de aprendizagem pode ser visto em goo.gl/B8jwCM.

${ }^{4}$ Gráfico com detalhamento das etapas de ensino contempladas segundo a RSL pode ser vista em goo.gl/hRYsTi.
} 
interessantes sobre este questionamento. Segundo Alencar et al. (2015), que apresentou o aplicativo Whatsapp como ferramenta de apoio ao ensino, observou-se que

\begin{abstract}
em especial os professores brasileiros, são resistentes a inserção de tecnologias em sala de aula, já que esses estão inseridos em um mundo de práticas pedagógicas tradicionais, não permitindo a mudança e o processo de incluir novas tecnologias na escola. (ALENCAR et al., 2015, p. 788)
\end{abstract}

Freitas (2016), que apresentou uma proposta de minicurso voltado ao uso de smartphone para fins educacionais, atribuiu a referida resistência em utilizar as novas tecnologias ao medo e dificuldade de manipular dispositivos tecnológicos.

Porém, felizmente este cenário, pouco a pouco vem apresentando mudanças. No caso ilustrado por Nascimento e Filho (2016), uma professora do ensino de ciências do $7^{0}$ ano buscou colocar em prática um projeto que abordasse conteúdos trabalhados em sala e também fizesse uso de tecnologias móveis. Para isso, ela buscou ajuda junto à pesquisadora autora do artigo a fim de obter orientações e êxito na implementação do projeto.

De forma semelhante, o estudo apresentado por Pereira et al. (2016b) aconteceu graças à consonância de interesses dos pesquisadores e uma escola estadual que solicitou ao grupo de pesquisa uma formação tecnológica para os professores, para que os mesmos pudessem aprender a usar Tecnologias Digitais em sala de aula.

Estes relatos demonstram que gradativamente a consciência da importância das TIC na educação tem sido incorporada. Para Leite (2014), os desafios que se materializam agora não dizem respeito à disponibilidade de informações ou conteúdo, mas à habilidade de identificar e avaliar de forma crítica quais recursos devem ser utilizados, os por quê e para quê a fim de adaptá-los às necessidades de formação e comunicação.

\title{
QP5. As experimentações têm sido associadas às teorias de aprendizagem?
}

Quarenta e três por cento (43\%) dos trabalhos investigados nesta RSL não fizeram menção à associação a alguma das teorias de aprendizagem. Os demais trabalhos citaram influencias das teorias Vygotskianas (22\%), Construtivismo (14\%), Conectivismo (7\%) e Outras Teorias (15\%).

Em "outras teorias" foram contabilizadas teorias comportamentais citadas por Kurtz et al. (2015) que se embasaram no estudo das teorias do Flow, TAM (Modelo de Aceitação de Tecnologia) e TBP (Teoria do Comportamento Planejado).

Diante dos dados apurados, observa-se que existe uma carência de adoção de teorias de aprendizagem. Esta situação pode revelar fatores limitantes ao potencial educacional 
das abordagens voltadas para a aprendizagem móvel. No entanto, não foi verificado uma disparidade de êxitos nos casos apresentados em virtude da utilização ou não das teorias de aprendizagem. Contudo, ressaltamos que o aporte pedagógico oferecido pelas Teorias só tende a enriquecer as experiências educacionais em quaisquer contextos.

\section{CONSIDERACOOES FINAIS}

Este artigo apresentou uma Revisão Sistemática de Literatura que teve por objetivo principal conhecer o panorama das publicações científicas nacionais sobre a utilização de aplicativos móveis sem fins educacionais aplicados aos processos de ensino e aprendizagem.

Após extração e análise dos dados levantados, foi verificado que, embora as ações de integração relacionadas ao tema pesquisado ainda se mostrem tímidas, tem havido um aumento de publicações apresentando casos de sucesso envolvendo a aprendizagem móvel. No entanto, acreditamos que ainda existe um longo caminho a ser percorrido para garantir que estes casos se estendam a um número maior de escolas.

Por vivenciarmos um período em que o crescimento do uso de celulares tem se mostrado uma tendência, os dados aqui levantados apontam que o cenário da educação atual se mostra cada vez mais propício a utilizações de aplicações móveis em sala de aula.

\section{REFERÉNCIAS}

ALENCAR, G.A et al. WhatsApp como ferramenta de apoio ao ensino. In: IV Congresso Brasileiro de Informática na Educação e X Conferência Latino-Americana de Objetos e Tecnologias de Aprendizagem. Anais dos Workshops do IV Congresso de Informática na Educação. Maceió, 2015.

ALMEIDA, M. E. B. de. Currículo e narrativas digitais em tempos de ubiquidade: criação e integração entre contextos de aprendizagem. Revista de Educação Pública, v.25, p.526546, 2016.

ALMEIDA, M. E. B. de. TIC na Educação: Políticas Públicas e Currículo. Anais do Colóquio Web Currículo: contexto, aprendizado e conhecimento, 1.: 2015, São Paulo, SP.

ALMEIDA, M. E.B. de.; VALENTE, J. A. Integração Currículo e Tecnologias e a Produção de Narrativas Digitais. Currículo sem Fronteiras, v. 12, p. 57-82, 2012.

BRASIL. Secretaria Nacional de Juventude (SNJ). Agenda juventude Brasil: pesquisa nacional sobre perfil e opinião dos jovens brasileiros. Brasília, DF: SNJ, 2013. Disponível em: $\quad<$ http://juventude.gov.br/participatorio/participatorio/agenda-juventude-brasil-vejaversaoatualizada\#.VyiZjdlrKM8>. 
CASTELLS, Manuel. A sociedade em Rede. A era da informação: economia, sociedade e cultura, vol. 1. Tradução Roneide Venancio Majer. 17ª Edição. São Paulo: Paz e Terra, 2016.

FREITAS, B. F. Telas que Ensinam: Smartphones e Aplicativos de Celular na Construção de Vídeos Instrucionais para Sala de Aula. In: Congresso Regional sobre Tecnologias na Educação. Natal, 2016.

HITZSCHKY, R. A. et al. Práticas educativas com o uso de dispositivos móveis em aulas de campo: aprendizagem para além dos muros da escola. In: Congresso Regional sobre Tecnologias na Educação. Natal, 2016.

IBGE. Acesso à internet e à televisão e posse de telefone móvel celular para uso pessoal : 2015 / IBGE, Coordenação de Trabalho e Rendimento. - Rio de Janeiro : IBGE, 2016. Disponível em: < http://biblioteca.ibge.gov.br/visualizacao/livros/liv99054.pdf>. Acesso em: 13 de março de 2017.

KENSKI, Vani M. Reflexões e indagações sobre a sociedade digital e a formação de um novo profissional/professor. Revista Latinoamericana de Tecnología Educativa, v. 3, p. 99107, 2004.

KITCHENHAM, B.; CHARTERS, S. Guidelines for performing Systematic Literature Reviews in Software Engineering. 2.3 ed. Durham, 2007.

KURTZ, R. et al. Fatores de impacto na atitude e na intenção de uso do m-learning: um teste empírico. Revista Eletrônica de Administração, v.21, p.27-56, 2015.

LEITE, B.S. M-Learning: o uso de dispositivos móveis como ferramenta didática no Ensino de Química. Revista Brasileira de Informática na Educação, v.22, n.3. p.55-68, 2014.

LÉVY, Pierre. Cibercultura. Tradução de Carlos Irineu da Costa. 1aㅡ Edição. São Paulo: Editora 34, 1999.

LOPES, R.T.; PEREIRA, A.C.; SILVA, M.A.D. Análise Comparativa da Familiaridade e Uso das TIC por Alunos de Odontologia. Revista Brasileira de Educação Médica, v.40, p. 254260, 2016.

MARÇAL, E. et al. Análise do uso de mensagens de celular na melhoria da participação de estudantes em cursos a distância: um estudo de caso. Novas Tecnologias na Educação, v.14, n. 2. p. 1-10, 2016.

MARINHO, S.P.P. et al. Tecnologias Móveis, Mídias e Redes Sociais: Cultura de uso de estudantes de licenciatura. In: IV Congresso Brasileiro de Informática na Educação e X Conferência Latino-Americana de Objetos e Tecnologias de Aprendizagem. Anais dos Workshops do IV Congresso de Informática na Educação. Maceió, 2015.

NASCIMENTO, K.A.S.; FILHO, J.A.C. Dispositivos móveis na educação: ensinando e aprendendo em diferentes contextos. In: $\mathrm{V}$ Congresso Brasileiro de Informática na Educação. Anais do XXVII Simpósio Brasileiro de Informática na Educação. Uberlândia, 2016.

PEREIRA, A.B.C. et al. Jogos Digitais no desenvolvimento de conceitos matemáticos sob perspectiva BYOD e abordagem $\mathrm{m}$-Learning na escola pública. In: $\mathrm{V}$ Congresso Brasileiro 
de Informática na Educação. Anais do XXII Workshop de Informática na Escola. Uberlândia, 2016a.

Mathematics Experiences: pedagogical implications with the use of digital games, m-learning and social networks. In: XI Latin American Conference on Learning Objects and Technology. Costa Rica, 2016b.

Pesquisa sobre o uso das tecnologias de informação e comunicação nas escolas brasileiras: TIC educação 2015 [livro eletrônico] = Survey on the use of information and communication Technologies in brazilian schools: ICT in education 2015/ Núcleo de Informação e Coordenação do Ponto BR, [editor] - São Paulo: Comitê Gestor da Internet no Brasil, 2016.2 Disponível em: < http://cetic.br/media/docs/publicacoes/2/TIC_Edu_2015_LIVRO_ELETRONICO.pdf > Acesso em 03 de fevereiro de 2017.

SANTAELLA, Lucia. Culturas e artes do pós-humano: da cultura das mídias à cibercultura. [coordenação Valdir José de Castro]. - 4ª Edição. São Paulo: Paulus, 2003.

UNESCO, Organização das Nações Unidas para a Educação, a Ciência e a Cultura. Padrões de Competência em TIC para Professores.2009. Disponível em: < http://unesdoc .unesco.org/ images /0015/001562/156209por.pdf> Acesso em: 02 de fevereiro de 2017. 